\title{
ALaRMED: adverse events in low-risk chest pain patients receiving continuous ECG monitoring in the emergency department: a survey of Canadian emergency physicians
}

\author{
Clare L. Atzema, MD, MSc; Michael J. Schull, MD, MSc
}

\begin{abstract}
Objective: Current guidelines suggest that most patients who present to an emergency department (ED) with chest pain should be placed on a continuous electrocardiographic monitoring (CEM) device. We surveyed emergency physicians to determine their perception of current occupancy rates of CEM and to assess their attitudes toward prescribing monitors for low-risk chest pain patients in the ED.

Methods: We conducted a cross-sectional, self-administered Internet and mail survey of a random sample of 300 members of the Canadian Association of Emergency Physicians. Main outcome measures included the perceived frequency of fully occupied monitors in the ED and physicians' willingness to forgo CEM in certain chest pain patients.

Results: The response rate was $66 \%$ (199 respondents). The largest group of respondents ( $43 \%$; $95 \%$ confidence interval $[\mathrm{Cl}] 36 \%-50 \%$ ) indicated that monitors were fully occupied $90 \%-100 \%$ of the time during their most recent ED shift. When asked how often they were forced to choose a patient for monitor removal because of the limited number of monitors, $52 \%(95 \% \mathrm{Cl}$ $45 \%-60 \%)$ of respondents selected $1-3$ times per shift. Ninety percent $(95 \% \mathrm{Cl} 84 \%-93 \%)$ of respondents indicated that they would forgo CEM in certain cardiac chest pain patients if there was good evidence that the risk of a monitor-detected adverse event was very low.

Conclusion: Emergency physicians report that monitors are often fully occupied in Canadian EDs, and most are willing to forgo CEM in certain chest pain patients. A large prospective study of CEM in low-risk chest pain patients is warranted.
\end{abstract}

Keywords: survey, chest pain, equipment, emergency department, monitor

\section{RÉSUMÉ}

Objectif : Les directives actuelles recommandent la surveillance électrocardiographique continue (SÉC) pour la plupart des patients qui se présentent à l'urgence avec des douleurs thoraciques. Nous avons sondé les médecins d'urgence pour déterminer leur perception quant au taux d'utilisation actuel des appareils de SÉC et évaluer leurs attitudes à l'égard de la prescription de la SÉC pour les patients à l'urgence présentant des douleurs thoraciques à faible risque.

From the Division of Emergency Medicine, Sunnybrook Health Sciences Centre, Toronto, Ont.

Submitted July 17, 2007; Revised Feb. 20, 2008; Accepted Feb. 21, 2008

This article has been peer reviewed.

CJEM 2008;10(5):413-9 
Méthodes : Nous avons effectué une enquête transversale auto-administrée, par voie postale et par le biais du Web, auprès d'un échantillon aléatoire de 300 membres de l'Association canadienne des médecins d'urgence. Les principales mesures des résultats comprenaient la fréquence perçue de pleine utilisation des appareils de SÉC dans les salles d'urgence et la volonté des médecins de renoncer à la SÉC pour certains patients ayant des douleurs thoraciques.

Résultats : Le taux de réponse était de $66 \%$ (199 répondants). Le groupe le plus important de répondants [43\%, intervalle de confiance (IC) à $95 \%, 36$ à $50 \%$ ] a indiqué que les moniteurs étaient utilisés 90 à $100 \%$ du temps, lors de leur plus récent quart de travail à l'urgence. Lorsque I'on a demandé aux répondants combien de fois ils étaient contraints de choisir un patient à qui enlever le moniteur en raison du nombre limité d'appareils, $52 \%$ (IC à $95 \%, 45$ à $60 \%$ ) ont répondu " une à trois fois par quart de travail ». Quatre-vingt-dix pour cent (IC à $95 \%, 84$ à $93 \%$ ) des répondants ont indiqué qu'ils renonceraient à la surveillance électrocardiographique continue chez certains patients ayant des douleurs thoraciques si le risque que le moniteur permette de détecter un événement indésirable était très faible.

Conclusion : Les médecins d'urgence rapportent que les moniteurs sont souvent utilisés à pleine capacité dans les salles d'urgence au Canada. La plupart d'entre eux sont disposés à renoncer à I'utilisation de la SÉC pour certains patients ayant des douleurs thoraciques. Une étude prospective à grande échelle portant sur l'utilisation d'appareils de SÉC pour les patients présentant des douleurs thoraciques à faible risque s'impose.

\section{Introduction}

Currently in Canada and the United States, most patients who present to an emergency department (ED) with chest pain are placed on a continuous electrocardiographic monitoring (CEM) device. Because of an increased risk of a fatal arrhythmia in patients experiencing an acute myocardial infarction, ${ }^{1,2}$ both the Canadian Association of Emergency Physicians (CAEP) and the American Heart Association stipulate that patients who have chest pain that could be due to ischemia should receive CEM. ${ }^{3,4}$ Several studies have questioned the use of routine CEM for hospital inpatients with chest pain, citing negligible benefits in those who are deemed "very-low risk." ${ }^{5-7}$ However, ED chest pain patients are significantly different from their inpatient counterparts for 2 opposing reasons. First, most do not have an acute coronary syndrome. ${ }^{8}$ Second, and conversely, those with an acute coronary syndrome are at a higher risk of an adverse event early in the course of their disease when they are in the ED. ${ }^{9}$ Two recent studies of standard CEM in ED chest pain patients found a very low adverse event rate. ${ }^{10,11}$

Emergency physicians could be helped by a tool that identifies patients for whom CEM can be safely omitted or stopped, yet the use of such a tool would likely depend on how often monitored beds are unavailable in our current ED environment. Because of the growing demand for care in the ED, ${ }^{12,13}$ in particular for higher acuity patients,,${ }^{14}$ and increased ED crowding, we reasoned that the availability of ED beds with CEM may have decreased. Indiscriminate use of CEM for all chest pain patients, including lower risk patients, could deny high-risk patients the benefits of $\mathrm{CEM}^{5,15}$ and increase nursing time and associated costs. ${ }^{10}$ However, if CEM capacity is rarely overwhelmed, then it is unlikely that emergency physicians would forgo CEM even for low-risk patients, and conducting a prospective study on the utility of ED CEM may not be justified. The objectives of this study were to determine the degree of perceived monitor shortage in Canadian EDs, to assess clinician attitudes toward CEM and to assess physician comfort with forgoing CEM in lower risk ED chest pain patients.

\section{Methods}

\section{Study design and population}

This was a cross-sectional, self-administered, mixed-mode survey (with an Internet and a mail component). The Sunnybrook Health Sciences Centre Review Ethics Board approved the study.

\section{Study subjects}

We identified emergency physicians on the CAEP membership roster. Using a computer-generated random selection procedure, we selected 300 attending physicians and residents from the 1324 members who were not medical students. Because physicians who work solely in a pediatric emergency medicine facility are not identified on the membership roster, they were included in the initial selection process. If subjects were not working clinically they were asked to use their last clinical experience to answer 
the survey, provided it was within 5 years. Exclusion criteria included members who did not have a Medical Doctorate (MD) degree or those who had not worked clinically for more than 5 years in a Canadian ED that serves adults.

\section{Survey questionnaire and administration}

The questionnaire consisted of questions that asked respondents

- about CEM in a hypothetical chest pain patient, using multiple scenarios;

- how useful CEM has been in their practice for identifying adverse events (defined as an hemodynamically significant arrhythmia or vital sign abnormality);

- about openness to forgoing CEM and under what circumstances, including whether the patient is classified as "low-risk" using a validated Acute Coronary Syndrome assessment tool;

- how often monitors were fully occupied in the ED; and

- demographic information.

The questionnaire was pilot tested on a convenience sample of 10 emergency physicians, resulting in only minor changes. Nonrespondents were compared with respondents using the number of years since their graduation from medical school, their sex and province of employment.

Survey administration began on June 1, 2004, using the Dillman Tailored Design Method for mail and Internet surveys. ${ }^{16}$ Nonrespondents received 2 email reminders 2 weeks apart, and incorrect email addresses were replaced with correct addresses when possible (using Internet searches). Next, a mail survey was sent to email nonrespondents, followed by a reminder postcard 2 weeks later. Mail surveys that were "returned to sender" were readdressed using hospital addresses found through the websites of provincial licensing colleges.

\section{Data analysis}

Internet survey responses were electronically downloaded into an Excel 2000 (Microsoft Corp.) file by the survey site. Subsequent mail responses were manually entered into the Excel file by 2 research assistants using double data entry. We addressed data quality control using range and logic checks. To avoid bias created by missing data, we tested the randomness of our missing data ${ }^{17}$ (i.e., if missing values were randomly distributed across all observations) by comparing respondents with and without missing data on several demographic variables. Single imputation was planned if random missing data constituted less than $5 \%$ of the data. ${ }^{17}$ For the primary analysis, we used descriptive statistics, including frequency distributions and proportions with 95\% confidence intervals (CIs).
We prespecified 2 secondary analyses of interest:

1. Was the emergency physician's willingness to ever remove CEM associated with their sex, the number of years since their graduation from medical school and their hospital type?

2. Was the proportion of the ED shifts during which the monitors were fully occupied associated with the hospital type and ED census?

Analyses were conducted using $\chi^{2}$ or Fisher exact test, or the Kruskal-Wallis test, as appropriate, using SAS software, version 8.2 (SAS Institute, Inc.).

\section{Results}

Of the 300 physicians initially selected, 199 responded $(66 \%)$. Eight respondents were removed from the analysis, 1 who did not possess an MD and 7 who had practised pediatric emergency medicine exclusively in the previous 5 years, leaving 191 final respondents (Table 1). Missing items constituted $0.7 \%$ of all responses and were missing at random.

When respondents were asked what percentage of the time monitors were fully occupied during their most recent ED shift, $43 \%$ (95\% CI 36\%-50\%) of respondents selected $90 \%-100 \%$ of the time, while another $19 \%$ (95\% CI 14\%-26\%) indicated 66\%-75\% (Fig. 1). One-half of respondents $(52 \%$; 95\% CI 45\%-60\%) reported being forced to remove CEM from a patient to provide a monitor for a sicker patient between 1 and 3 times per shift (Fig. 2).

One-quarter of respondents (26\%; 95\% CI 20\%-33\%) indicated that they would be comfortable caring for between $26 \%$ and $50 \%$ of their monitored ED chest pain patients without a monitor, and another one-quarter $(25 \%$; 95\% CI 19\%-31\%) said that they would be comfortable caring for between $11 \%$ and $25 \%$ of these patients without a monitor. One-half of respondents $(54 \%$; $95 \% \mathrm{CI}$ $47 \%-61 \%$ ) indicated that they had found CEM helpful in identifying adverse events in ED chest pain patients between $1 \%$ and $5 \%$ of the time during the previous year.

For a patient with chest pain that was suspected to be cardiac in origin who had no abnormal ST or T wave changes on ECG, no arrhythmias and no abnormal vital signs, 171 respondents (90\%; 95\% CI 84\%-93\%) indicated that they would consider discontinuing CEM after initial assessment if there was good scientific evidence that CEM detects a negligible number of adverse events in these patients. Of every 4 respondents, 3 (73\%; $95 \%$ CI $66 \%-79 \%$ ) reported that $0.1 \%$ was an acceptable miss rate, when respondents who chose a higher acceptable miss rate were included (Fig. 3). One-quarter of the 
respondents (23\%; 95\% CI 17\%-29\%) chose $1 \%$ as an acceptable miss rate.

There was a trend toward a willingness to discontinue CEM by type of facility ( $p=0.06$ ), with $95 \%$ of respondents from teaching sites (95\% CI 88\%-99\%) indicating that they would ever consider discontinuing CEM, compared with $85 \%$ from community sites (95\% CI $76 \%-92 \%)$ and $84 \%$ from rural sites (95\% CI 60\%-92\%).
Hospital type was associated with the percentage of time that monitors were fully occupied $(p<0.001$; Fig. 4$)$, with subjects at teaching centres reporting fully occupied monitors more often than those at community hospitals, and community sites more often than rural sites. A similar result was found by ED census $(p<0.001)$, with sites with more than 60000 visits annually reporting fully occupied monitors more often than lower census sites.

Table 1. Demographic and practice characteristics of survey respondents

\begin{tabular}{|c|c|c|}
\hline \multirow[b]{2}{*}{ Characteristic } & \multicolumn{2}{|c|}{ Group; no. (and \%) } \\
\hline & Respondents & Nonrespondents \\
\hline \multicolumn{3}{|l|}{ Practice } \\
\hline Full-time ED clinician & $124(65)$ & - \\
\hline Part-time ED clinician & $47(25)$ & - \\
\hline ED clinician: not working in ED 1-4 yr & $3(1.5)$ & - \\
\hline Resident & $16(8)$ & - \\
\hline Other & $1(0.5)$ & - \\
\hline \multicolumn{3}{|l|}{ Years since graduation from medical school } \\
\hline $0-3$ & $13(7)$ & $6(7)$ \\
\hline $4-7$ & $39(20)$ & $15(18)$ \\
\hline $8-11$ & $38(20)$ & $13(16)$ \\
\hline $12-16$ & $36(19)$ & $15(18)$ \\
\hline $17-21$ & $24(13)$ & $8(10)$ \\
\hline$>21$ & $41(21)$ & $25(31)$ \\
\hline \multicolumn{3}{|l|}{ Sex } \\
\hline Female & $43(23)$ & $21(21)$ \\
\hline Male & $148(77)$ & $79(79)$ \\
\hline \multicolumn{3}{|l|}{ Province of current employment } \\
\hline Atlantic* & $19(10)$ & $13(13)$ \\
\hline Quebec & $12(6)$ & $5(5)$ \\
\hline Ontario & $96(50)$ & $46(45)$ \\
\hline Prairiet & $36(19)$ & $19(19)$ \\
\hline Nunavut, Northwest Territories, Yukon & $1(1)$ & $0(0)$ \\
\hline British Columbia & $24(13)$ & $15(14)$ \\
\hline Other location $\ddagger$ & $3(2)$ & $3(3)$ \\
\hline \multicolumn{3}{|l|}{ Type of practice facility } \\
\hline Rural hospital & $19(10)$ & - \\
\hline Community hospital & $89(46.5)$ & - \\
\hline Teaching hospital & $82(43)$ & - \\
\hline Other & $1(0.5)$ & - \\
\hline \multicolumn{3}{|l|}{ Annual ED census of hospital } \\
\hline$<20000$ & $10(6)$ & - \\
\hline $20000-40000$ & $54(28)$ & - \\
\hline $40000-60000$ & $68(36)$ & - \\
\hline$>60000$ & $59(31)$ & - \\
\hline \multicolumn{3}{|l|}{ Catheterization lab at hospital } \\
\hline No & $113(59)$ & - \\
\hline Yes & $78(41)$ & - \\
\hline \multicolumn{3}{|c|}{$\begin{array}{l}\text { ED = emergency department. } \\
\text { *Atlantic provinces: Nova Scotia, Newfoundland and Labrador, New Brunswick and Prince Edward } \\
\text { Island. } \\
\text { tPrairie provinces: Alberta, Manitoba and Saskatchewan. } \\
\text { fOther locations of employment included areas outside of Canada: Unites States, Saudi Arabia and } \\
\text { United Arab Emirates. }\end{array}$} \\
\hline
\end{tabular}




\section{Discussion}

The first steps in creating a clinical decision-making instrument include determining whether it is needed and whether clinicians will use it, as well as establishing the acceptable missed adverse event rate. In this study, we established that limited monitoring capacity is perceived to be a problem by Canadian emergency physicians, with most reporting that monitors are fully occupied most of the time. This is notable because it suggests that many EDs cannot meet the current standards ${ }^{3,4}$ for monitoring chest pain patients most of the time. We found that $90 \%$ of Canadian emergency physicians would consider discontinuing monitoring if there were good scientific evidence that the likelihood of detecting an adverse event was very low. One-half of surveyed Canadian emergency physicians and residents indicated that they would be comfortable caring

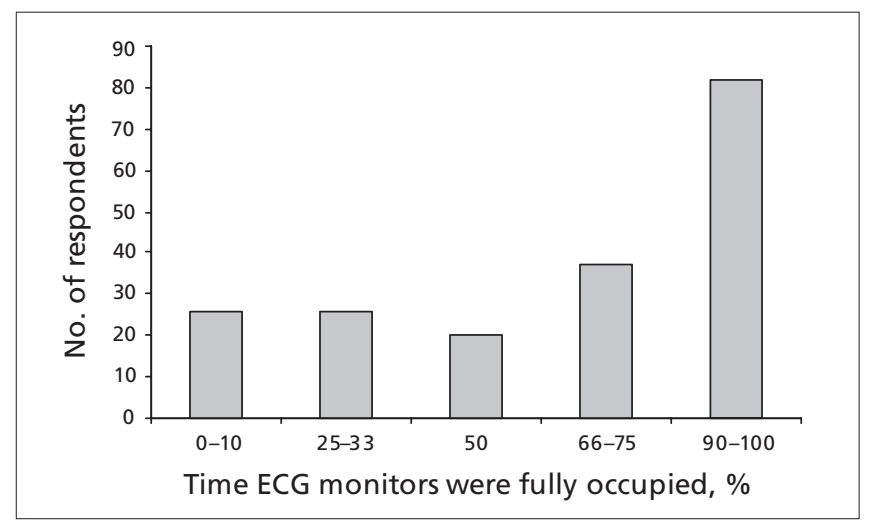

Fig. 1. Percentage of time that continuous cardiac (electrocardiogram [ECG]) monitors were fully occupied during the respondents' most recent shift in the ED (there were 7 nonrespondents). Respondents selected from a list of discrete values, collapsed here into 5 ranges for clarity.

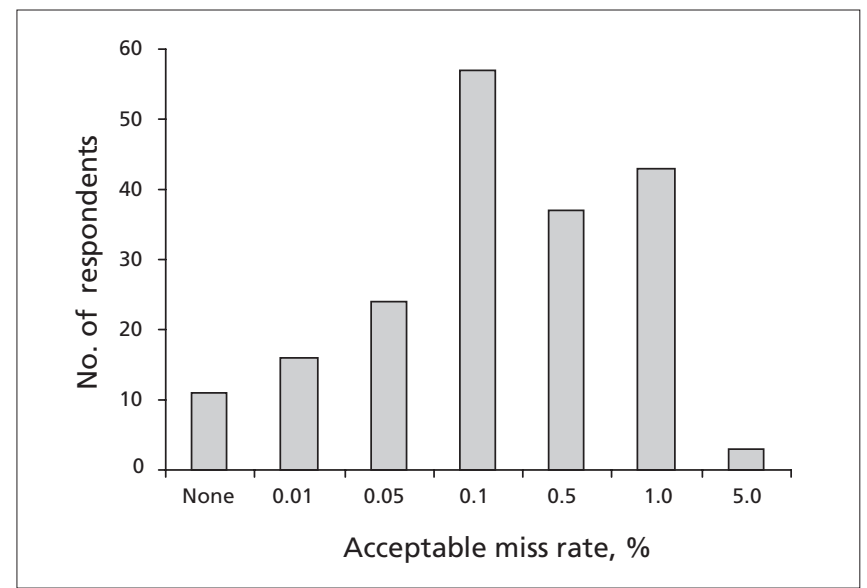

Fig. 3. The acceptable risk of missed monitor-detected adverse events if monitors were not used in low-risk chest pain patients. for a substantial proportion of the chest pain patients they see without CEM. Thus it seems that a clinical decision instrument to direct CEM would likely be used. Such a change in practice could provide significant relief in the context of a shortage of monitoring capacity.

In our secondary analysis we found that fully occupied monitors were reported more commonly at teaching and community hospitals than at rural hospitals, which may relate to greater crowding that has previously been reported at high-volume centres. ${ }^{18}$ Therefore, emergency physicians working in higher volume sites may be more likely to need or use a clinical decision instrument to guide CEM. However, even if monitors are fully occupied only one-third of the time in small-hospital EDs, this may be important given limitations in transferring patients and in staffing at these smaller sites.

No tool, including clinical intuition, is perfect or without

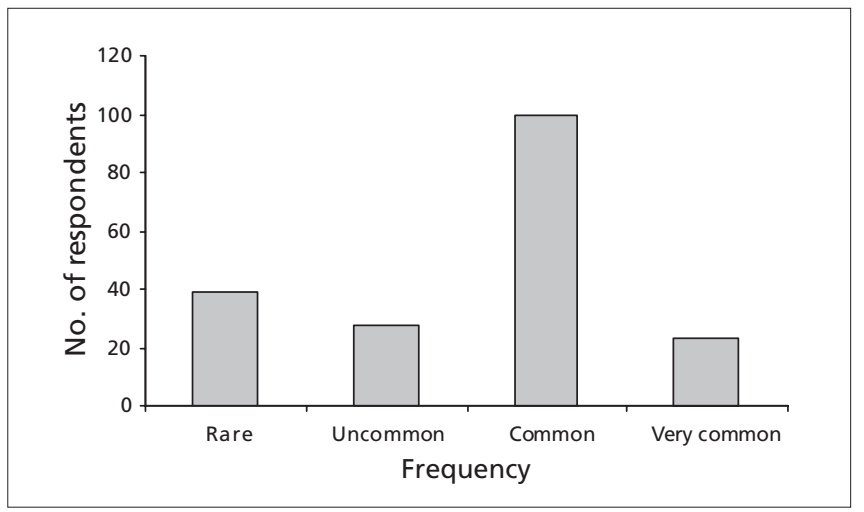

Fig. 2. Frequency that respondents have to remove a cardiac monitor from a patient to provide it for a sicker patient. Rare = less than once per 6 shifts; Uncommon = once per every 1-3 shifts; Common $=1-3$ times per shift; Very common $=$ greater than 5 times per shift.

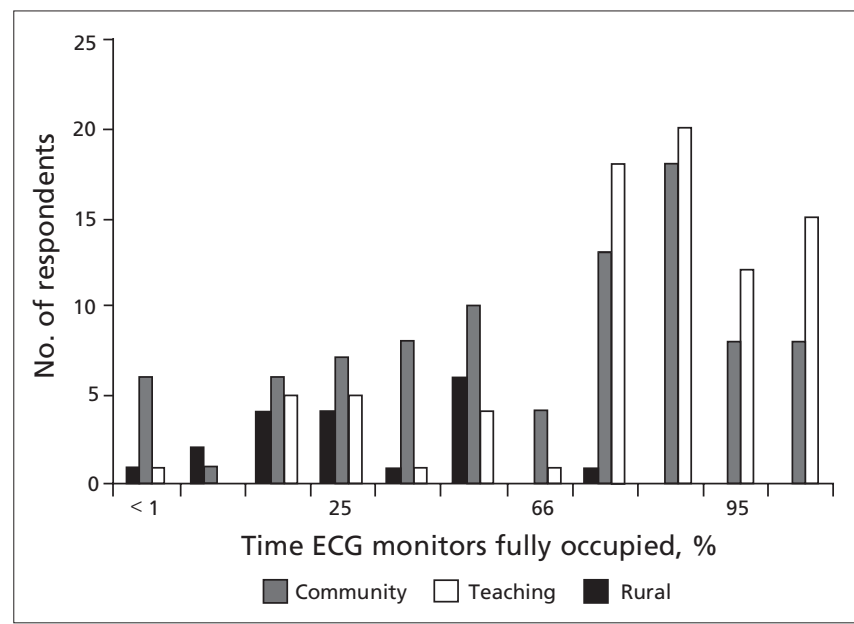

Fig. 4. Percentage of time that electrocardiogram (ECG) monitors were reported fully occupied, by hospital type. 
cost, so there must be a miss rate. An eventual clinical decision instrument should prespecify an acceptable boundary for adverse event rates in ED chest pain patients who do not require CEM and it should also compare this with the miss rate for the current practice of using clinical intuition to address a shortage of monitoring capacity. In this study, we found that a miss rate for monitor-detected adverse events of up to $0.1 \%$ was acceptable to the large majority of emergency physicians and that one-quarter would accept a miss rate of $1 \%$. The Goldman risk score is a simple, prospectively derived and validated tool that identified a group of ED chest pain patients with a risk of a major adverse event of $0.2 \%$. However, this is a much lower miss rate than most clinical decision rules can detect and it required over 10000 patients in the derivation phase. A recent decision instrument derived by Gatien and colleagues ${ }^{11}$ on 992 ED chest pain patients had $100 \%$ sensitivity to detect arrhythmia that required an intervention, but the lower CI was $80 \%$, which would not be acceptable to most emergency physicians, according to the results of this study.

The acceptable adverse event miss rate indicated by our respondents might have changed if other clinical decision instrument miss rates had been included in the survey for comparative reference, such as in the derivation of the Canadian head CT rule (lower CI of 92\%) ${ }^{19}$ and C-spine instruments (lower CI of 98\%). ${ }^{20}$ We also recognize that there may be some bias introduced by the selection of responses offered by the survey (with $0.1 \%$ being a middle value), rather than letting respondents decide their own rate. Given the limitations of our study, the appropriate missed adverse event rate for an eventual decision instrument remains to be clearly established, particularly in comparison with the adverse event rate of clinical intuition.

Despite fully occupied monitors, some emergency physicians may be unwilling to forgo CEM for other reasons, including a conservative practice style, convenience of vital sign recording, resistance from other consultants, or perceived utility for reasons other than detection of lifethreatening events (all of which participants noted in the open comments section of the survey). The challenge remains, however, to allocate a scarce resource in an environment that cannot support unlimited monitoring indefinitely.

\section{Limitations}

Although $66 \%$ is a good response rate for surveys, it does leave a large proportion of potential respondents who may have different practices and attitudes that may have affected our results. It is somewhat reassuring that nonrespondents were not significantly different from respondents by sex, province of employment and the number of years since their graduation from medical school. However, it is quite possible that CAEP members do not represent all Canadian emergency physicians accurately, resulting in a selection bias in our study. A small sample size also limits the power of our statistical analyses, but we purposely chose to survey only a proportion of the CAEP membership to avoid bothering all members with another survey request. Fortunately, these were secondary questions that were of interest but not the primary purpose of the project, which was to describe the degree of perceived monitor shortage in Canadian EDs and to assess clinician attitudes toward CEM. Last, monitor occupancy rates were an estimate provided by physicians and not a direct measurement. However, there is probably no better way to estimate how occupied monitors are across the country than asking the individuals who work in the ED, and we specifically asked about monitor use in their last ED shift rather than a general impression of occupancy rates.

\section{Conclusion}

Fully occupied monitors are a problem in Canadian EDs and frequently require emergency physicians to prioritize their use. The large majority of Canadian emergency physicians would be willing to forgo monitoring in certain ED chest pain patients if good evidence demonstrated that it detected a very low number adverse events in these patients.

Funding: This project was supported by a CAEP Research Grant.

Competing interests: None declared.

\section{References}

1. Julian DG, Valantine PA, Miller GG. Disturbances of rate, rhythm and conduction in acute myocardial infarction. Am J Med 1964;37:915-27.

2. Spann JF, Moellering RC, Haber E, et al. Arrhythmias in acute myocardial infarction. A study utilizing an electrocardiographic monitor for automatic detection and recording of arrhythmias. N Engl J Med 2005;271:427-31.

3. Beveridge R, Clarke B, Janes L, et al. Implementation guidelines for the Canadian Emergency Department Triage and Acuity Acale (CTAS). 2003. Available: www.caep.ca/template .asp $? \mathrm{id}=98758372 \mathrm{CC} 0 \mathrm{~F} 45 \mathrm{FB} 826 \mathrm{FFF} 49812638 \mathrm{DD}$ (accessed 2008 July 22).

4. Drew BJ, Califf RM, Funk M, et al. Practice standards for electrocardiographic monitoring in hospital settings: an American Heart Association scientific statement from the Councils on Cardiovascular Nursing, Clinical Cardiology, and Cardiovascular Disease in the Young: endorsed by the International Society of Computerized Electrocardiology and the American Association of Critical-Care Nurses. Circulation 2004;110:2721-46.

5. Durairaj L, Reilly B, Das K, et al. Emergency department 
admissions to inpatient cardiac telemetry beds: a prospective cohort study of risk stratification and outcomes. Am J Med 2001; 110:7-11.

6. Hollander JE, Valentine SM, McCuskey CF, et al. Are monitored telemetry beds necessary for patients with nontraumatic chest pain and normal or nonspecific electrocardiograms? Am J Cardiol 1997;79:1110-1.

7. Hollander JE, Sites FD, Pollack CV Jr, et al. Lack of utility of telemetry monitoring for identification of cardiac death and lifethreatening ventricular dysrhythmias in low-risk patients with chest pain. Ann Emerg Med 2004;43:71-6.

8. Pope JH, Aufderheide TP, Ruthazer R, et al. Missed diagnoses of acute cardiac ischemia in the emergency department. N Engl J Med 2000;342:1163-70.

9. Goldman L, Cook E, Johnson P, et al. Prediction of the need for intensive care in patients who come to emergency departments with acute chest pain. N Engl J Med 1996;334:1498-504.

10. Atzema C, Schull MJ, Borgundvaag B, et al. ALARMED: adverse events in low-risk patients with chest pain receiving continuous electrocardiographic monitoring in the emergency department. A pilot study. Am J Emerg Med 2006;24:62-7.

11. Gatien M, Perry JJ, Stiell IG, et al. A clinical decision rule to identify which chest pain patients can safely be removed from cardiac monitoring in the emergency department. Ann Emerg Med 2007;50:136-43

12. Derlet R, Richards J, Kravitz R. Frequent overcrowding in US emergency departments. Acad Emerg Med 2001;8:151-5.

13. Schull MJ, Szalai JP, Schwartz B, et al. Emergency department overcrowding following systematic hospital restructuring: trends at twenty hospitals over ten years. Acad Emerg Med 2001;8: 1037-43.

14. Lambe S, Washington DL, Fink A, et al. Trends in the use and capacity of California's emergency departments, 1990-1999. Ann Emerg Med 2002;39:389-96.

15. Bayley MD, Sanford Schwartz J, Shofer FS, et al. The financial burden of ED congestion and hospital overcrowding for chest pain patients awaiting admission. Acad Emerg Med 2002;9:367.

16. Dillman DA. Mail and Internet surveys: the tailored design method. 2nd ed. New York (NY): John Wiley \& Sons; 2000.

17. Newgard CD, Haukoos JS. Advanced statistics: missing data in clinical research - part 2: multiple imputation. Acad Emerg Med 2007; 14:669-78.

18. Rowe B, Bond K, Ospina B, et al. Frequency, determinants, and impact of overcrowding on emergency departments in Canada: a national survey of emergency department directors. Health Quarterly 2007;10:32-40.

19. Stiell IG, Wells GA, Vandemheen K, et al. The Canadian CT Head Rule for patients with minor head injury. Lancet 2001; 357:1391-6.

20. Hoffman JR, Mower WR, Wolfson AB, et al. Validity of a set of clinical criteria to rule out injury to the cervical spine in patients with blunt trauma. National Emergency X-Radiography Utilization Study Group. N Engl J Med 2000;343:94-9.

Correspondence to: Dr. Clare Atzema, Division of Emergency Medicine, Sunnybrook Health Sciences Centre, 2075 Bayview Ave., Rm. G157, Toronto ON M4N 3M5; clare.atzema@ices.on.ca 